\title{
AVALIAÇÃO DO TEOR DE TANINOS DA ESPÉCIE VEGETAL Combretum leprosum Mart. (MUFUMBO)
}

MOURA, T. P. G. (IFRN) ${ }^{1}$; ALVES, L. A. (IFRN)²; BERTINI, L.M. (IFRN) ${ }^{3}$

priscila.moura_21@hotmail.com ${ }^{1}$; leonardo.alcantara@ifrn.edu.br²; luciana.bertini@ifrn.edu.br ${ }^{3}$

\section{RESUMO}

No Brasil, várias espécies são pesquisadas por suas propriedades tanantes. Os taninos são compostos secundários, presentes na maioria das plantas, que podem variar de concentração nos tecidos vegetais. Dentre as várias espécies vegetais utilizadas para fins medicinais, a Combretum leprosum Mart., conhecida popularmente como mufumbo, por possuir uma atividade antiinflamatoria comprovada, tem despertado interesse para o estudo da mesma devido aos seus beneficios. No presente trabalho, os extratos da Combretum leprosum Mart. foram submetidos a testes para a quantificação do teor de taninos onde obteve-se resultados de 310,$8 ; 436,3$ e 3,3 ppm para folhas, galhos e raiz, respectivamente. Com isso, conclui-se que é de grande importância o estudo dessa espécie vegetal, para a comprovação de suas atividades biológicas, uma vez que a mesma já possui um histórico muito rico no uso fitoterápico.

\section{TANNINS CONTENT ASSESSMENT OF VEGETABLE SPECIES Combretum leprosum MART. (MUFUMBO)}

\begin{abstract}
In Brazil, several species are surveyed for its tanning properties. Tannins are secondary compounds present in most plants, which can vary in concentration in plant tissues. Among the various plant species used for medicinal purposes, Combretum leprosum Mart., Popularly known as mufumbo, for having an antiinflammatory activity proven, has aroused interest in the study of the same due to its benefits. In this study,
\end{abstract}

extracts of Combretum leprosum Mart. underwent tests to quantify the tannin content which was obtained results of $310.8 ; 436.3$ and 3.3 ppm for leaves, branches and roots, respectively. Thus, it follows that is of great importance the study of this plant species, for proof of their biological activities, since it already has a very rich history in herbal medicine use.

KEY-WORDS: folk medicine, tannins, secondary metabolites. 


\section{INTRODUÇÃO}

Taninos são metabólitos secundários presentes na maioria das plantas, que podem variar de concentração nos tecidos vegetais, dependendo da idade e tamanho da planta, da parte coletada, da época ou, ainda, do local de coleta. No Brasil, várias espécies são pesquisadas por suas propriedades tanantes (TEIXEIRA et al., 1990; SIMON et al.,1999; LARCHER, 2000).

Estes são compostos fenólicos de grande interesse econômico e ecológico, apresentam solubilidade em água e peso molecular compreendido entre 500 e 3000 Dalton (MELLO et al., 2001), possuindo a habilidade de formar complexos insolúveis em água com proteínas, gelatinas e alcalóides. Tais compostos são responsáveis pela adstringência de muitos frutos e produtos vegetais devido a precipitação de glucoproteínas salivares, o que ocasiona perda do poder lubrificante (BRUNETON, 1991).

Pesquisas sobre atividade biológica dos taninos evidenciaram importante ação contra determinados microrganismos, como agentes carcinogênicos e causadores de toxicidade hepática. Estes últimos efeitos, sem dúvida, dependem da dose e do tipo de tanino ingerido. A ingestão de chá verde e de dietas ricas em frutas que contêm taninos tem sido associada com atividade anticarcinogênica. Além disso, podem agir como antiinflamatórios, cicatrizantes e inibidores de HIV (CHUNG et al., 1998).

O Combretum leprosum Mart., conhecido como mufumbo ou mofumbo, é uma planta encontrada em estados do Nordeste brasileiro, principalmente Piauí e Ceará, e possui atividade anti-inflamatória comprovada (SILVA, 2009). Popularmente, é utilizado no tratamento de diarreias, dores de dente, como antiofídica e na cicatrização de feridas. Alguns estudos com essa espécie demonstraram ação antinociceptiva em modelos de dor aguda, e outras espécies do gênero também mostraram ação anti-inflamatória (PIETROVSKI et al., 2010). Estudos previamente realizados no Núcleo de Pesquisas em Plantas Medicinais (NPPM) da UFPI mostraram que o Combretum leprosum é muito eficaz como antinociceptivo em modelos de dor, e especificamente no teste da formalina, o qual demonstrou além de sua ação analgésica, atividade anti-inflamatória (DE BARROS et al, 2009).

Com isto, o presente artigo tem como objetivo avaliar os extratos da Combretum leprosum Mart (Mufumbo) no que se refere à concentração de taninos e dessa forma adquirir conhecimento sobre a viabilidade de utilização dessa planta para fins medicinais.

\section{MATERIAIS E MÉTODOS}

\subsection{Obtenção do material vegetal}

A matéria prima utilizada na obtenção dos extratos do Combretum leprosum Mart. (mufumbo) foi obtida na zona rural do município de Apodi-RN. O material foi previamente separado por folhas, galhos e raiz, sendo estes triturados e pesados.

\subsection{Análise do teor de Taninos}

Esta análise foi realizada conforme Broadhurst e Jones (1978), empregando-se a catequina como padrão. O material vegetal (folhas, galhos e raiz) (100 mg) foram extraídos com $1 \mathrm{~mL}$ de solução acetona:água (70:30, v/v) em banho de água a 30 C por $30 \mathrm{~min}$, com agitação em aparelho Vortex a cada $5 \mathrm{~min}$. As amostras foram centrifugadas a $10.000 \mathrm{rpm}$ por 5 min e o sobrenadante coletado. A extração foi realizada mais 2 vezes, 
coletando os sobrenadantes no mesmo frasco. Os mesmos foram evaporados em banho maria até próxima a completa secagem e adicionados $2,5 \mathrm{~mL}$ de metanol. $0,1 \mathrm{~mL}$ da amostra foi adicionada a um tubo de ensaio contendo $0,9 \mathrm{~mL}$ de metanol. Ao tubo de ensaio foram adicionados $5 \mathrm{~mL}$ do reagente de vanilina (sendo $2,5 \mathrm{~mL}$ de solução de $1 \mathrm{~g}$ de vanilina em $100 \mathrm{~mL}$ de metanol e outros $2,5 \mathrm{~mL}$ de solução contendo $8 \mathrm{~mL}$ de $\mathrm{HCl}$ concentrado em $100 \mathrm{~mL}$ de metanol). Os tubos foram deixados em banho de água por 20 minutos. Uma amostra em branco foi realizada utilizando solução de $\mathrm{HCl} 4 \%$ em metanol. A absorbância foi medida em espectrofotômetro a $500 \mathrm{~nm}$. O teor de taninos foi obtido a partir da plotagem do valor observado em curva de calibração previamente realizada utilizando catequina.

\section{RESULTADOS E DISCUSSÕES}

Através do estudo quantitativo dos extratos do mufumbo foi possível determinar o teor de taninos condensados presentes em suas folhas, galhos e raízes. Os resultados obtidos estão apresentados na Tabela 1 a seguir:

Tabela 1: Teores condensados de taninos do cobretum leprosum mart. (Mufumbo)

\begin{tabular}{c|c}
\hline Material vegetal & Concentração de Taninos (ppm) \\
\hline Folhas & 310,8 \\
\hline Galhos & 436,3 \\
\hline Raiz & 3,3 \\
\hline
\end{tabular}

Com base nos dados vistos na tabela 1 é possível afirmar que os galhos do mufumbo apresentaram maior concentração de taninos com 436,3 ppm em relação as demais partes analisadas, seguido das folhas com 310,8, e o de menor concentração é a raiz com 3,3ppm. Sabendo que as concentrações encontradas variam de acordo com cada planta, de sua idade e de seu tamanho, segundo Monteiro et al. (2005).

Em comparação com o trabalho de Bezerra et al. (2015), estudando a concentração do teor de taninos dos extratos de Annona crassiflora (araticum), onde os valores quantificados foram: folhas $216,68 \mathrm{ppm}$, galhos $191,58 \mathrm{ppm}$, e raiz 172,75 , podese verificar que os valores das folhas e dos galhos do mufumbo são superiores ao do araticum, onde apenas a raiz possui um valor inferior.

\section{CONCLUSÃO}

Através do estudo da Cobretum leprosum Mart., pode-se obter resultados bastante satisfatórios no que se refere a quantidade de compostos tânicos, sendo que estes possuem um forte potencial farmacológico, mostrando assim a importância de se estudar essa espécie vegetal e confirmar as suas potencialidades terapêuticas.

\section{AGRADECIMENTOS}

Os autores agradecem ao Instituto Federal de Educação, Ciência e Tecnologia do Rio Grande do Norte - IFRN, Campus Apodi pela disponibilização do espaço cedido e ao Conselho Nacional de Desenvolvimento Científico e Tecnológico (CNPq) pelas bolsas concedidas e apoio financeiro para realização do projeto.

4ạ Semana de Química - IFRN, 2016 


\section{REFERÊNCIAS}

BEZERRA, A. P. F; NETO, F.B.O.; MORAIS, N.R.L. ;A. REBOUÇAS ' A.; ALVES, L. A.; BERTINI, L. M. DETERMINAÇÃO DO TEOR DE TANINOS DOS EXTRATOS DE Annona crassiflora (ARATICUM). Apodi. 2015.

BRUNETON, J.; Elementos de Fitoquímica y de Farmacognosia, Ed. Acribia, SA: Espanha, 1991.

CHUNG, K.; WEI, C.; JOHNSON, M. G.; Trends Food Sci. Technol. 1998, 9, 168.

DE BARROS FERNANDES, Heliana et al. ESTUDO DA AÇÃO ANTINOCICEPTIVA DE COMBRETUM LEPROSUM MART \& EICH EM MODELOS ANIMAIS DE DOR INFLAMATÓRIA. Curitiba. 2009.

LARCHER, W. Ecofisiologia vegetal. São Paulo: RiMa, 2000. 531p.

MELLO, J. P. C.; SANTOS, S. C. Em Farmacognosia: da planta ao medicamento; In: SIMÕES, C. M. O.; SCHENCKEL, E. P., orgs.; Ed. UFSC: Porto Alegre; 3ạ ed., 2001.

PIETROVSKI, Evelise Fernandes. Avaliaçao da atividade antinociceptiva do extrato etanólico e de princípios ativos obtidos das flores de Combretum leprosum Mart. 2010.

SILVA, C. D. Combretum leprosum Mart. (Combretaceae) - Avaliação da atividade antiinflamatória tópica em modelos de inflamação de pele agudo e crônico em camundongos.Dissertação de Mestrado, Curso de Pós-Graduação em Farmacologia UFPR. Curitiba, 2009.

SIMÓN, B. F.; CADAHIA, E.; CONDE, E.Evolution of phenolic compounds of spanish oak wood during natural seasoning. First results. Journal of Agricultural Food Chemistry, 47, p. $1687-1694,1999$.

TEIXEIRA, M. L.; SOARES, A. R.; SCOLFORO, J. R. S. Variação do teor de tanino da casca de barbatimão [Stryphnodendron adstringens (Mart.) Coville] em 10 locais de Minas Gerais. Ciência Prática, v. 14, n. 2, p. 229 - 232, 1990. 